LA WAENCE LISEAMCAE NATHONAL LABOAATOBY

\section{Composite Vessels for Containment of Extreme Blast Loadings}

J. Pastrnak, C. Henning, W. Grundler,

V. Switzer, R. Hollaway, J. Morrison, L.Hagler,

E. Kokko, S. DeTeresa, B. Hathcoat, E. Dalder

July 27, 2004

\section{PREPRINT}

American Society of Mechanical Engineers 2004 ASME Pressure Vessels \& Piping Division

Conference

San Diego, California July $25-29,2004$ 
This document was prepared as an account of work sponsored by an agency of the United States Government. Neither the United States Government nor the University of California nor any of their employees, makes any warranty, express or implied, or assumes any legal liability or responsibility for the accuracy, completeness, or usefulness of any information, apparatus, product, or process disclosed, or represents that its use would not infringe privately owned rights. Reference herein to any specific commercial product, process, or service by trade name, trademark, manufacturer, or otherwise, does not necessarily constitute or imply its endorsement, recommendation, or favoring by the United States Government or the University of California. The views and opinions of authors expressed herein do not necessarily state or reflect those of the United States Government or the University of California, and shall not be used for advertising or product endorsement purposes.

This work was performed under the auspices of the U.S. Department of Energy by University of California, Lawrence Livermore National Laboratory under Contract W7405-Eng-48. 


\title{
Composite Vessels for Containment of Extreme Blast Loadings
}

\author{
Authored by: J. Pastrnak, C. Henning, W. Grundler, V. Switzer, R. Hollaway, \\ J. Morrison, L.Hagler, E. Kokko, S. DeTeressa, B. Hathcoat, E. Dalder
}

\author{
American Society of Mechanical Engineers \\ 2004 ASME Pressure Vessels \& Piping Division Conference
}

\author{
San Diego, California \\ July $25-29,2004$
}

\begin{abstract}
A worldwide trend for explosives testing has been to replace open-air detonations with containment vessels, especially when any hazardous materials are involved. As part of the National Nuclear Security Administration's (NNSA) effort to ensure the safety and reliability of the nation's nuclear stockpile, researchers at Lawrence Livermore National Laboratory have been developing a high performance filament wound composite firing vessel that is nearly radiographically transparent. It was intended to contain a limited number of detonations of metal cased explosive assemblies in radiographic facilities such as the Advanced Hydrodynamic Facility (AHF) being studied by Los Alamos National Laboratory. A 2-meter diameter pressure vessel was designed to contain up to $35 \mathrm{~kg}(80 \mathrm{lb})$ of TNT equivalent explosive without leakage. Over the past 5 years a total of three half-scale ( 1 meter diameter) vessels have been constructed, and two of them were tested to $150 \%$ load with $8.2 \mathrm{~kg}$ (18-pound) spheres of C4 explosive. The low density and high specific strength advantages used in this composite vessel design may have other additional applications such as transporting sensitive explosives that could otherwise be moved only in very small quantities. Also, it could be used for highly portable, explosive containment systems for law enforcement.
\end{abstract}

\section{INTRODUCTION}

Lawrence Livermore National Laboratory (LLNL) has been collaborating with its sister laboratory, Los Alamos National Laboratory (LANL), to develop a filament-wound composite firing vessel for the containment of explosive experiments containing toxic and possibly radioactive materials. This facility, the Advanced Hydrodynamic Facility (AHF) in Figure 1, could contain limited amounts of nuclear materials. Accordingly, release of these materials might constitute a health risk. Public and worker exposure limits to toxic materials set many of the design criteria for these blast containment vessels.

The containment vessels must contain the dynamic blast impulse, the residual gas pressure of the explosive by-products, plus the high velocity fragments thrown from metal-cased experiments. Because they are primarily intended for high quality radiographic experiments, they must also be 
as thin as possible and made of less dense materials. Thicker vessels would of course provide a greater safety margin against failure but at the expense of the radiographic image quality (scatter and blur). To get around this dilemma, a system of nested containment vessels has been proposed which provides a defense-in-depth solution without overly reducing the radiographic transparency of the inner-most composite vessel of the containment system. The inner-most composite vessel (which is the subject of this paper) has been designed with three distinct functional layers, each of which is fairly independent of other failure threats. Vessel rupture resulting in gross leakage of toxic materials is prevented by a strong Kevlar composite structure that is over-wrapped or "wound" on an aluminum (sealing) liner. Blast generated fragments, jetting and shrapnel can be kept from perforating the sealing liner by installing ceramic shielding within the vessel. This paper covers some of the key development issues for composite firing vessels, including explosive experiments conducted with half-scale prototype vessels. Several innovative features introduced in this design include a seal monitoring system for leakage, friction stir welding of the aluminum pressure liner, and low noise fiber optic strain sensors as a structural diagnostic.

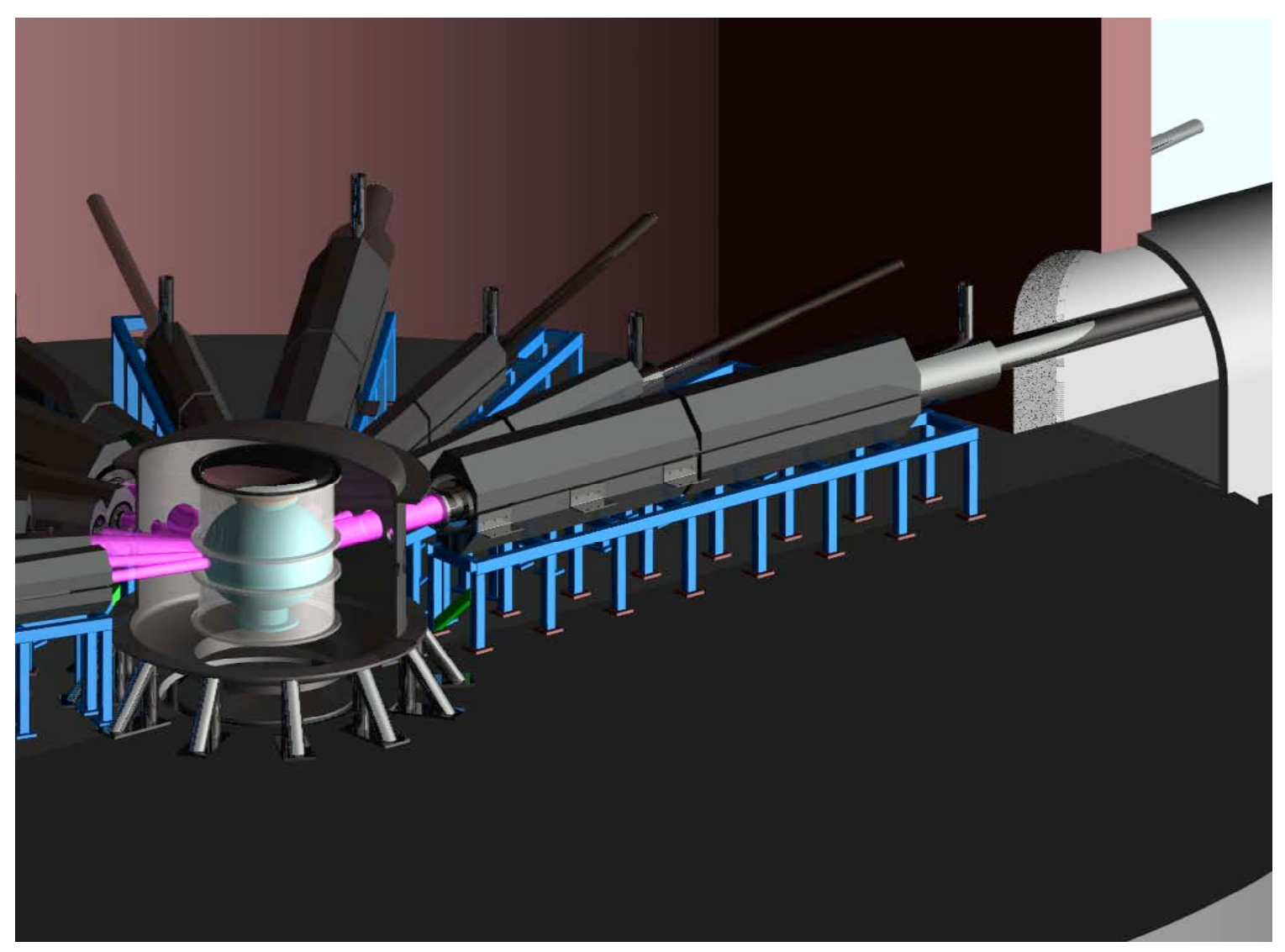

Figure 1

Containment system with inner-most Composite Firing Vessel with multiple proton beam radiographic lines of sight (AHF Firing Point) 


\section{DESIGN PHILOSOPHY}

Earlier conventional firing vessels have been made from steel with low density radiographic windows for up to 2 lines of sight. While thin beryllium windows in a steel vessel may be a possible alternative for AHF, practical window penetrations limit the number of lines of sight possible. They also require an early understanding of the viewing angles and window size. Since the exact number and location of lines of sight for a facility often cannot be specified before component development is begun, a vessel without "windows" that could accommodate any number of lines of sight is attractive.

The idea of a windowless low density filament-wound composite vessel was first considered at LLNL a few years ago when planning future stockpile stewardship facilities with multiple diagnostic X-ray lines of sight. We pursued low density materials and composites to improve Xray and/or proton beam penetration directly through the wall of the vessel. The resulting windowless vessel allows for multiple radiographic lines of sight without changing the structural design. Design flexibility is preserved, while the design and development can proceed. When experimenters need additional lines of sight for X-ray or proton imaging, they can be added without having to redesign and re-qualify the vessel. This approach is often necessary because government facilities of this type historically take at least 10 years until funding is obtained while design and development is proceeding.

For a given allowable material wall stress $(\sigma)$ the basic shape of the vessel of radius $(r)$ was chosen to be spherical in order to minimize the wall thickness $(t)$ and achieving a greater biaxial membrane stress efficiency by approximating a balanced stress state; $\sigma_{\text {hoop }}=\sigma_{\text {axial. }}$. A cylindrical vessel by contrast would for the same uniform internal static pressure $(P)$ require twice the wall thickness given by simple membrane theory:

$$
\begin{aligned}
\sigma_{\text {hoop }}=\frac{\operatorname{Pr}}{t} \quad \sigma_{\text {axial }}=\frac{\operatorname{Pr}}{2 t} & \text { cylinder } \\
\sigma_{\text {hoop }}=\sigma_{\text {axial }}=\frac{\operatorname{Pr}}{2 t} & \text { sphere }
\end{aligned}
$$

Another important criterion for firing vessels that is shared with static pressure vessels is the highly desired leak-before-break-criterion. By design, the composite firing vessel has its thinnest wall section near the equator; consequently this is the highest stressed area. If the aluminum liner fails by low cycle fatigue or gross rupture, the two halves of the liner sphere will still be held together by the continuous composite fiber structural over-wrap. Catastrophic failure of the vessel is prevented by engineering this weaker or fuse area into the structural design. However, the composite cannot prevent slow leakage. 


\section{VESSEL AND PORT CONFIGURATION}

The CVD (Composite Vessel Development) vessel shown in Figure 2 has a composite structure (Kevlar) with an ASTM 2219-T62 aluminum liner. This vessel is made of tough composite materials to withstand dynamic loadings. Low-density continuous aramid fibers with trade names such as Kevlar (CVD-2a) and Zylon (CVD-2b) make up the outer shell that provides the primary structural resistance against the blast forces. An aluminum load-sharing liner underneath provides a sealing surface to prevent gas leakage, supports the two polar openings, and doubles as the winding mandrel for the composite filaments. Ceramic materials (not shown) will be used inside for fragment protection of the aluminum pressure liner.

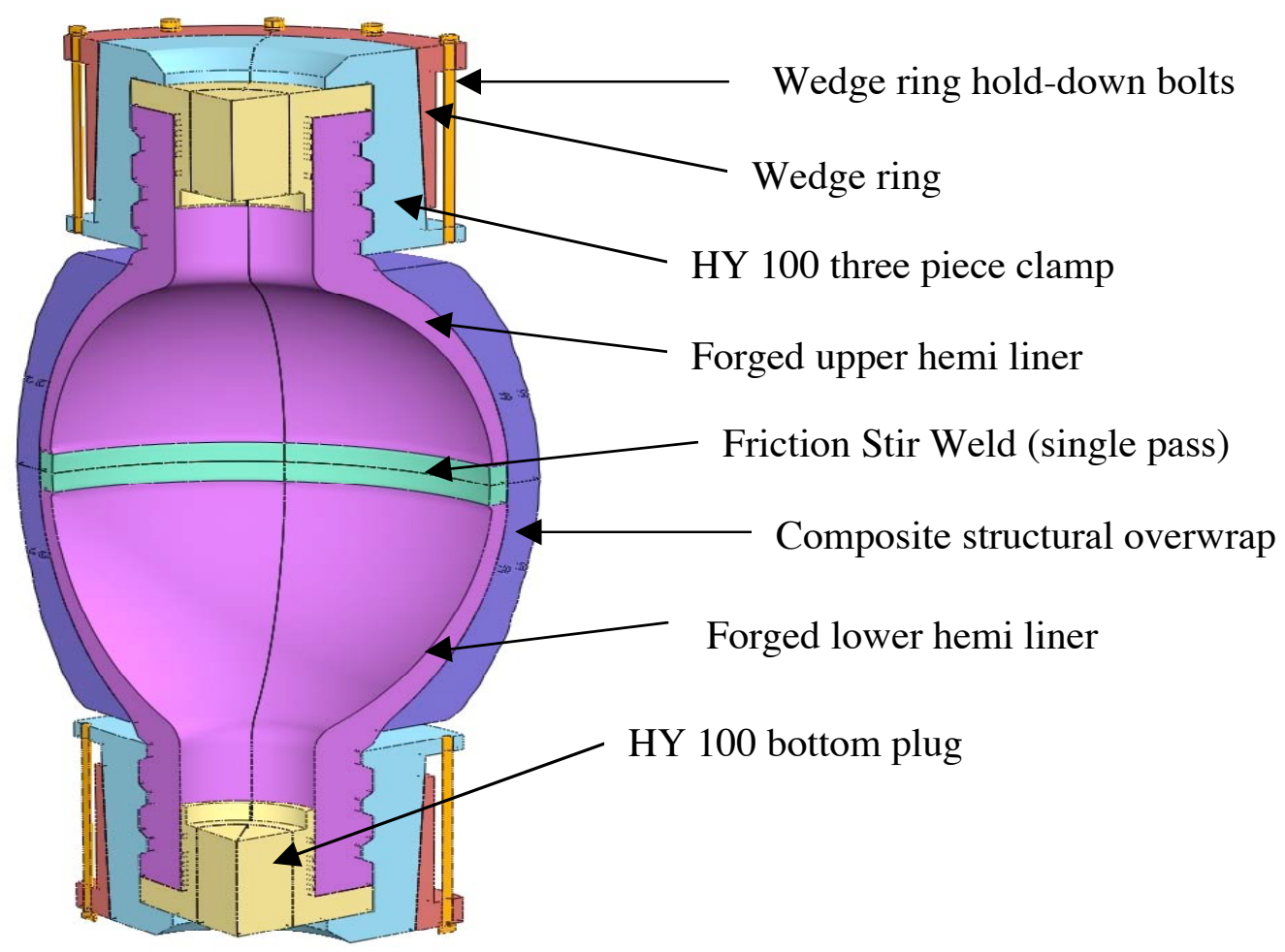

Figure 2. The CVD vessel is made with a filament wound composite structure, an aluminum liner, and steel plugs and clamps. 
An HY 100 steel plug shown in Figure 3 is inserted into the openings; it contains five dynamic O-rings on the bore of the plug and two static O-rings on the plug face. To prevent debris from damaging the first O-ring, a soft 1100-O aluminum wire was helically wound in the space below. The blast pressure integrated over the plug face resulted in a vertical blast force that tries to push the plug out of the bore. This force is restrained by a segmented and toothed HY 100 steel clamp and an outer wedge ring. The teeth on the clamps were designed to cause a radial force outward on the wedge ring and an equal reaction inward force on the aluminum port. Preload compression from the bolts and wedge ring was enough to press the bore of the aluminum liner elastically against the steel plug.

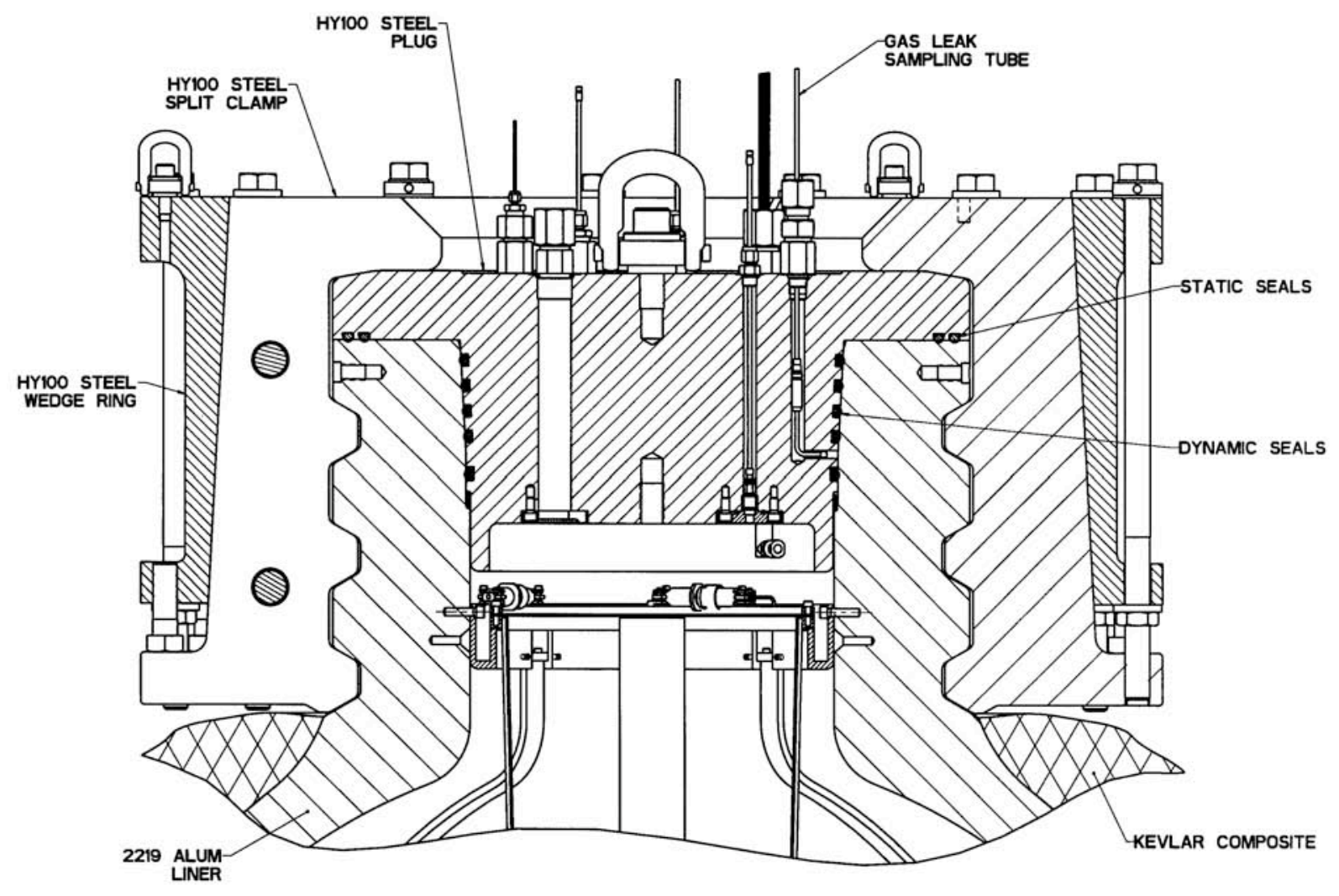

Figure 3- The two upper and lower ports were sealed by five dynamic and two static $\mathrm{O}$ rings. HY100 steel plugs were held in place by a split three piece clamp and outer wedge ring. 


\section{FABRICATION}

A previous method used to fabricate the aluminum liner of the first Kevlar wrapped half scale vessel CVD-1 proved to have weak welds during sustained testing. The vessel was progressively tested from $25 \%$ to $150 \%$ and eventually the liner failed due to poor Tungsten Inert Gas (TIG) welds that had low ductility and high porosity. The CVD-1 vessel had 6 pieces that were spinformed and TIG welded together. Its equatorial weld was not post weld solution heat treated like the other welds.

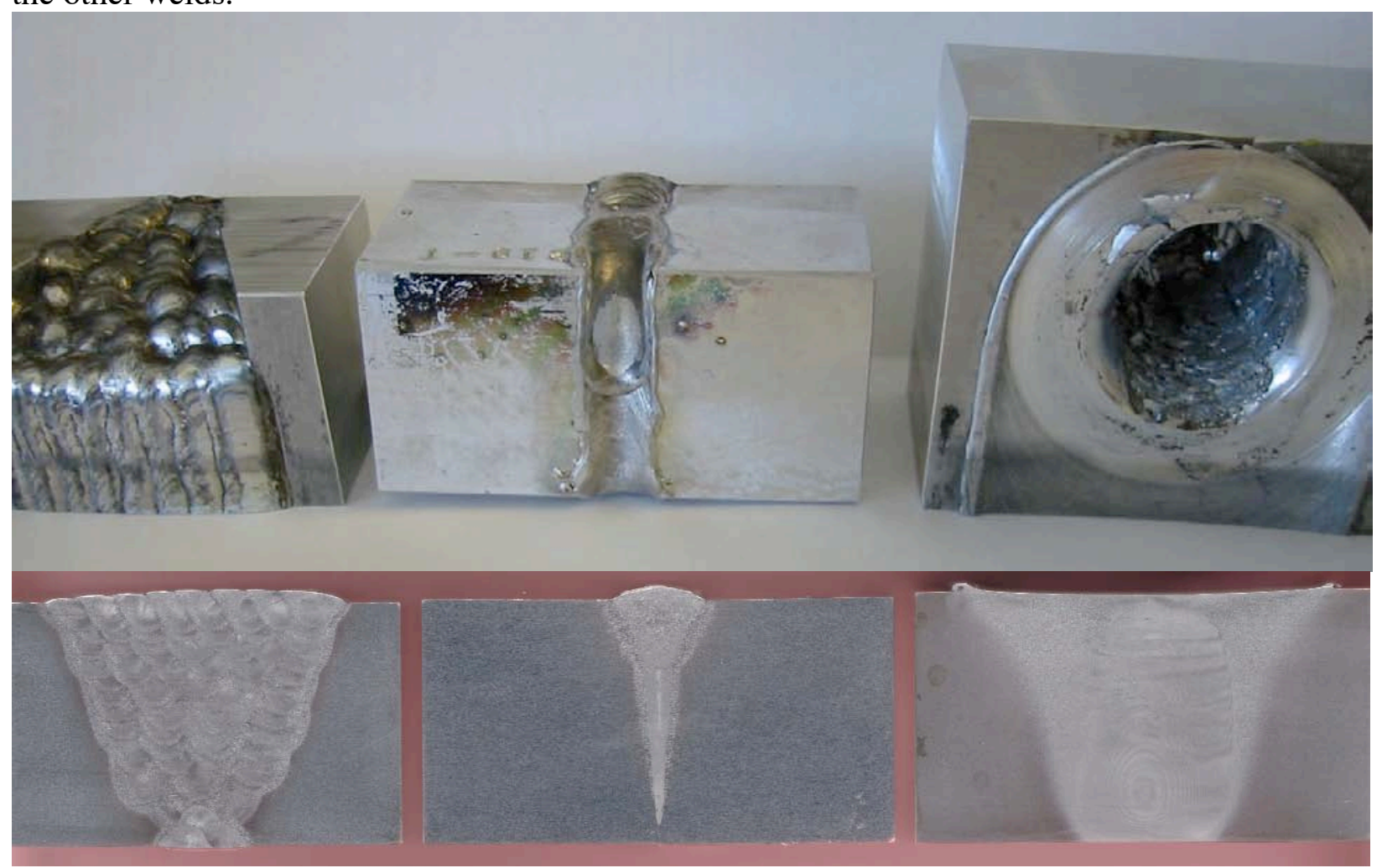

Figure 4. Available welding process candidate cross sections. From left ; multipass TIG, two pass E-beam, and single pass Friction Stir Weld.

In the search for a better joining technique to join the aluminum liner, Friction Stir Welding (FSW) was selected over Tungsten Inert Gas (TIG) and Electron Beam (EB) welding. FSW being a solid phase joining process does not suffer from post weld cracking and porosity. It does not require a filler material and is quite fast. Figure 5 shows the aluminum liner being welded in a single pass without filler material. It took about an hour to weld around the vessel with a single pass $38 \mathrm{~mm}$ (1.5") thick weld. 


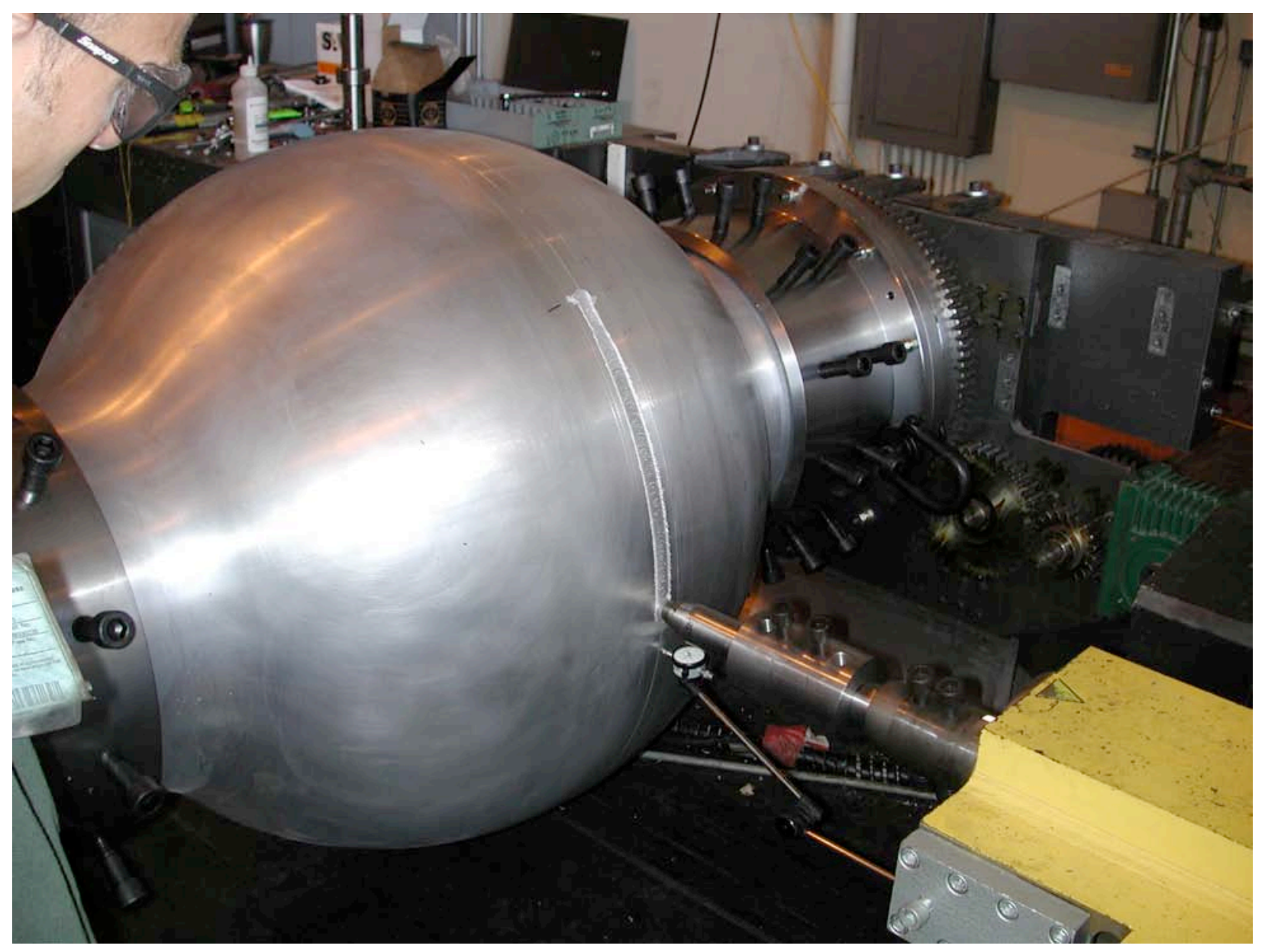

Figure 5. Friction Stir welding the aluminum liner in a single pass without filler material.

The aluminum liner was machined as shown in Figure 6 around the equator for smooth winding of the fiber composite. The end ports were precision machined to match the steel clamps that support the end plugs. Otherwise, the rough machined aluminum shell was close enough to the desired tolerances. 


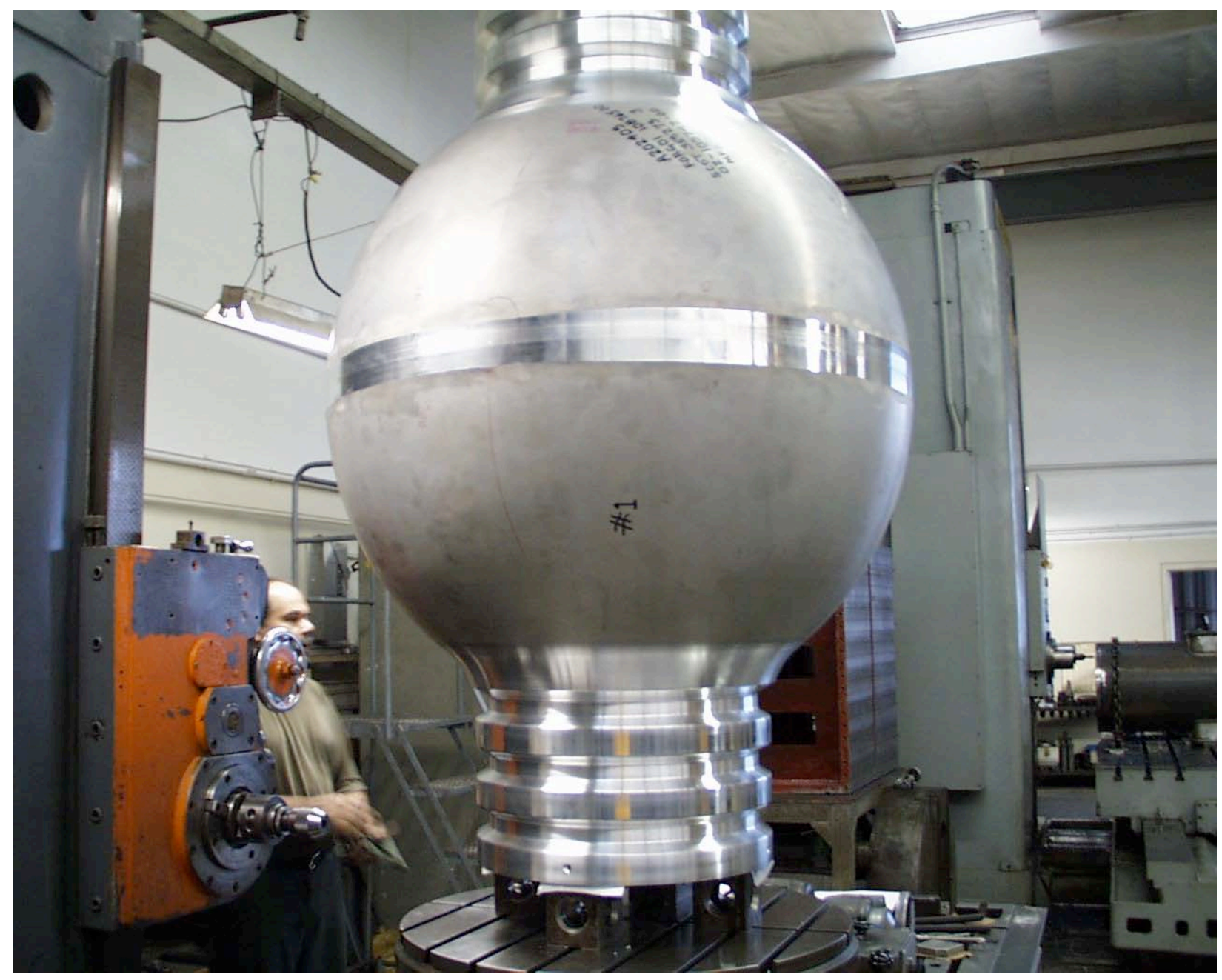

Figure 6. The aluminum liner was machined to take off roughness from the welds and then accurately machined at the ends to match the plug clamps.

After the aluminum liners were completed, two different composite wound vessels were constructed; Kevlar for (CVD-2a) and PBO for (CVD-2b). Both used an epoxy wet lay-up process and were completed in a few days. The epoxy cured at room temperature, so there was no differential thermal expansion to cause a gap to appear between the composite and the aluminum liner/mandrel. Fiber Bragg sensors were wound into the composite structure as a diagnostic to measure strain. These sensors were free from electrical noise because of their optical signal and fiber optic transmission lines. 


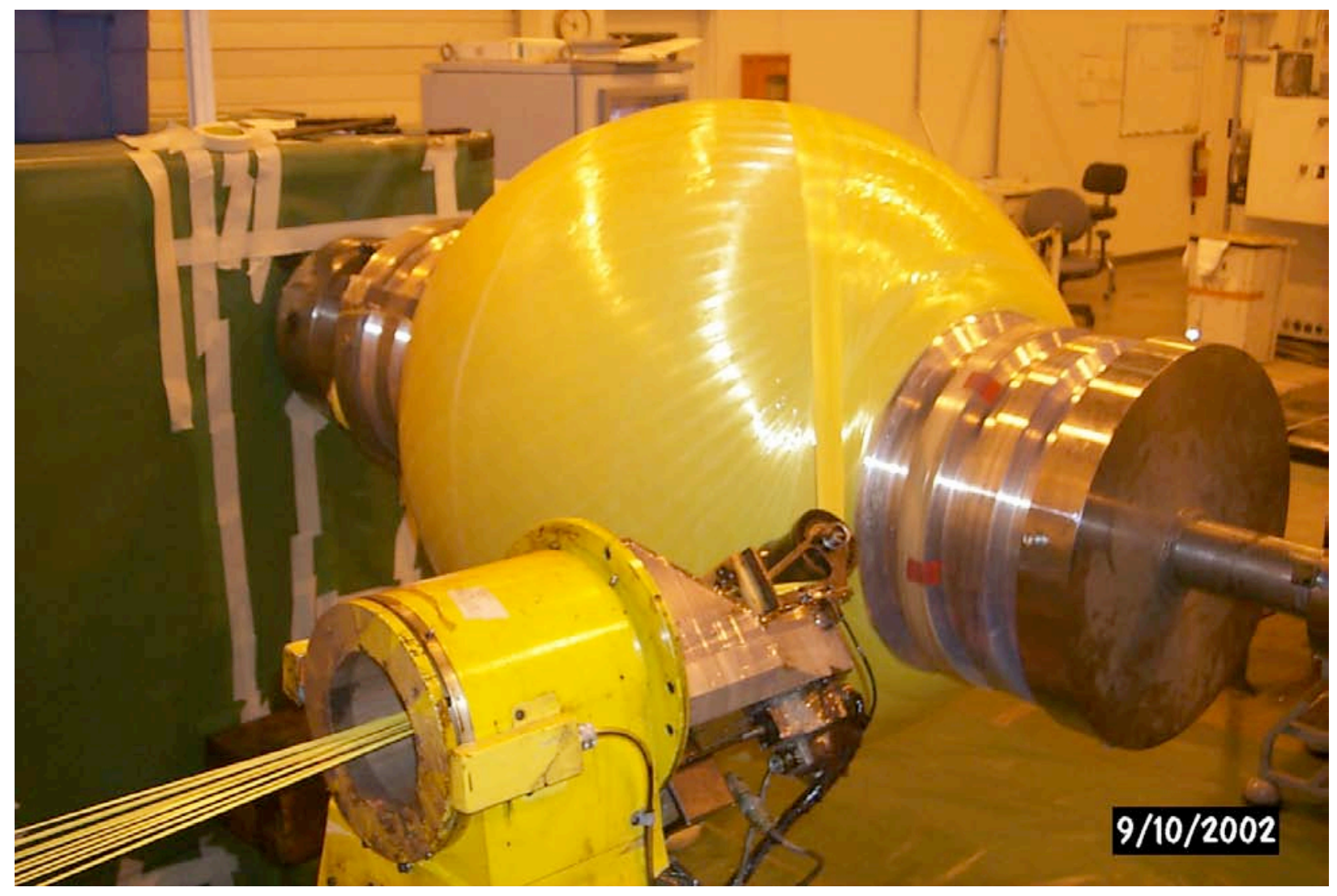

Figure 7- The composite vessel CVD-2 has a Kevlar structural wrap wound on a forged and Friction Stir Welded 2219-T62 aluminum liner. 


\section{DESIGN ANALYSIS}
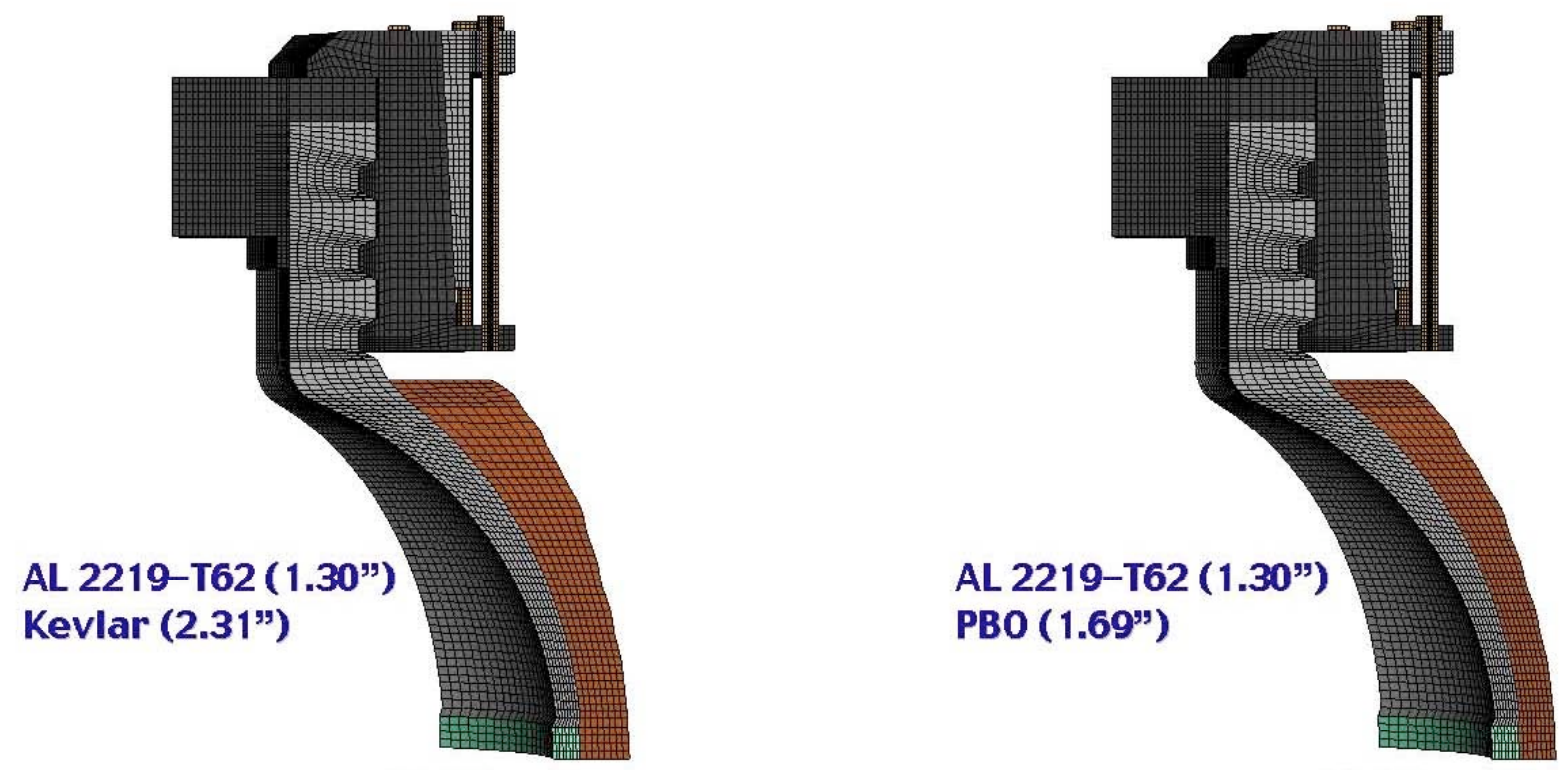

Figure 8- Sections through Kevlar and PBO over-wraped numerical models

The dynamic pressure loading for the vessel was determined by the CALE2D code for the specified weight of explosive. The pressure-time history was then transferred to a DYNA3D (three dimensional) model to begin the structural dynamic analysis. A three dimensional model shown in Figure 8 was used to assess the asymmetries in the three piece end clamp design. The special properties of the equatorial FSW weld region were included with properties based on experimental tests as shown in Figure 9. The fiber composite properties were calculated using a new LLNL ply orientation formatter (POF) in conjunction with CADWIND software to generate input for a new uni-directional elasto-plastic composite material model for this work. The new material model created is number 62 in DYNA3D.

Figure 10 shows a typical structural response of the vessel at a $150 \%$ overloaded condition. The most significant strain occurred near the equator of the aluminum liner. Instantaneous strains were about $1.5 \%$ and the accumulated effective plastic strain (EPS) was about $1.7 \%$. The aluminum material had an average of $8 \%$ strain to uniaxial failure, but was found to suffer low cycle fatigue after a few hundred cycles at $1-2 \%$ strain. 


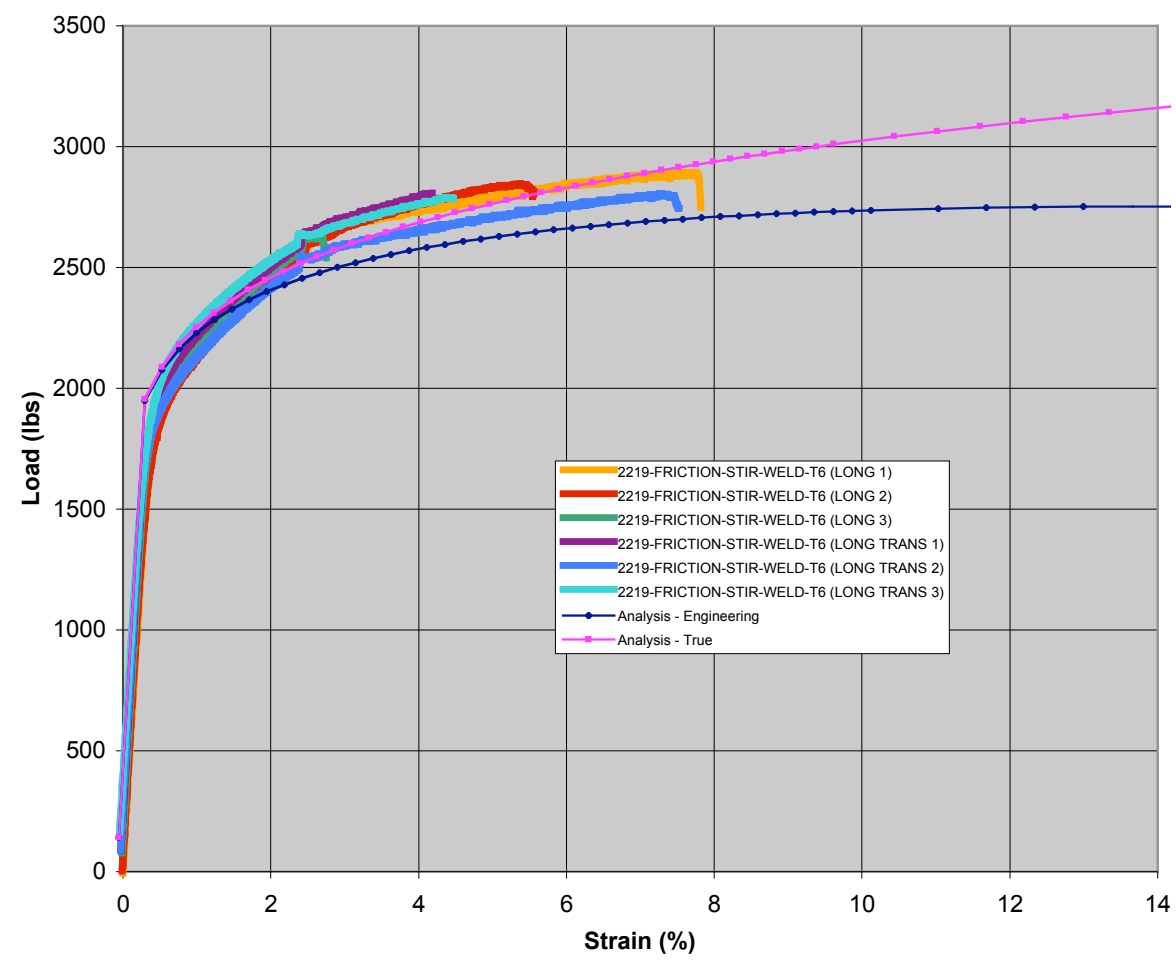

Figure 9- Load-Strain curves for the FSW material

These effective plastic strains are summarized in table I below. The elastic strains in the composite are shown in Table II. They are about $0.6 \%$ which is well below the $2.5 \%$ capability of the Kevlar fiber.

Table I Typical calculated effective plastic strains in the aluminum liner

\begin{tabular}{|l|l|l|l|}
\hline & \multicolumn{1}{|c|}{ Equator } & \multicolumn{1}{|c|}{ Above Weld } & \multicolumn{1}{|c|}{45 Degrees } \\
\hline CVD-2a & $1.6 \%(1.5 \%-1.9 \%)$ & $1.3 \%(0.56 \%-3.1 \%)$ & $\begin{array}{l}0.48 \%(0.36 \%- \\
0.63 \%)\end{array}$ \\
\hline CVD-2b & $1.5 \%(1.4 \%-1.8 \%)$ & $1.3 \%(0.44 \%-3.1 \%)$ & $\begin{array}{l}0.37 \%(0.26 \%- \\
0.55 \%)\end{array}$ \\
\hline
\end{tabular}

Table II Typical calculated strains in the composite materials at $\mathbf{1 5 0 \%}$ blast load conditions

\begin{tabular}{|l|r|r|}
\hline & Max Compressive & Max Tensile \\
\hline CVD-2a & $-0.16 \%$ & $0.59 \%$ \\
\hline CVD-2b & $-0.29 \%$ & $0.67 \%$ \\
\hline
\end{tabular}




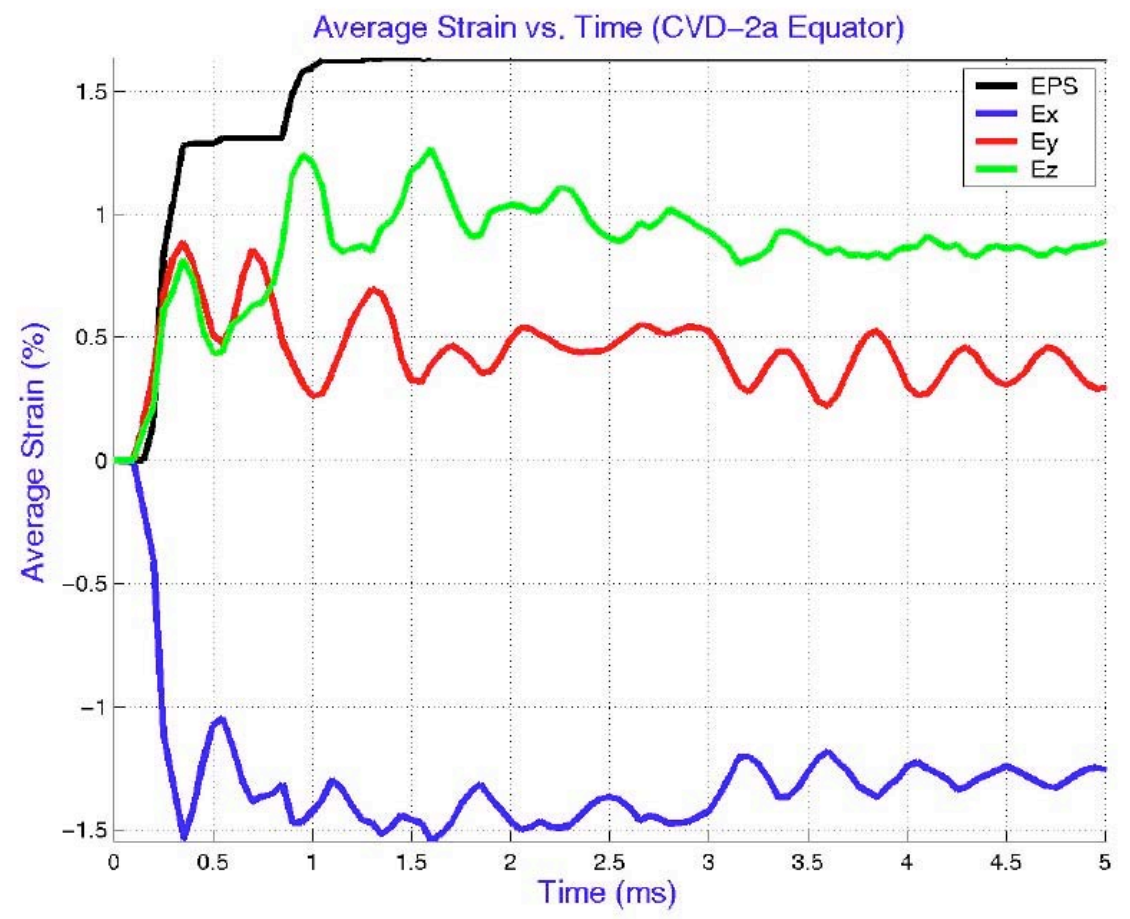

Figure 10. Typical structural response of the vessel showing strains in the aluminum liner to be about $1.5 \%$ and vibrations occurring with about a half millisecond period.

\section{LEAKAGE CONSIDERATIONS}

Transient leakage of hazardous materials such as uranium and beryllium particulates past the port seals needs to be prevented because of potential public and worker environmental hazards. Since no standard design codes exists for blast containment vessels of this type or purpose, we have reviewed the guidance of related consensus codes. It was assumed that the detection of a microgram of material would be sufficient for our development purposes and still be below existing standards.

Direct measurement of such small amount of particulate contaminants is difficult because they may remain in the seal space or be unevenly distributed on the vessel surfaces. Instead, a gas leakage method is used in accordance with the ANSI N14.5 Code. A maximum $\mathrm{U}^{233}$ particulateto-aerosol concentration of 9 micrograms per cubic centimeter of gas released was experimentally determined by Curren and Bond in the 1980 paper "Leakage of Radioactive Powders from Containers" [2]. Since up to 9 micrograms could be released in $1 \mathrm{cc}$ of gas, in order to detect just 1 microgram, then the gas leakage sensitivity should be about $0.1 \mathrm{cc}$ at standard atmospheric conditions. A complete description of the Seal Monitoring System which 
deals with any leakage of particulates and gases past the relatively soft O-ring seals at the vessel ports is the focus of another paper given by Henning et.al. [1].

\section{EXPERIMENTAL RESULTS}

The CVD2a vessel was instrumented with an array of strain gages and temperature sensors bonded to the vessel. Static and dynamic pressure transducers were mounted inside the vessel equator and attached to the top plug. The vessel and associated sensors were grounded and shielded to a single point to minimize the electrical noise generated by the ionized gas blast front. This method electrically floated the instrumentation, the sensor cable shields, and sensors. A preliminary 5\% explosive shot was used to check out the instrumentation system.

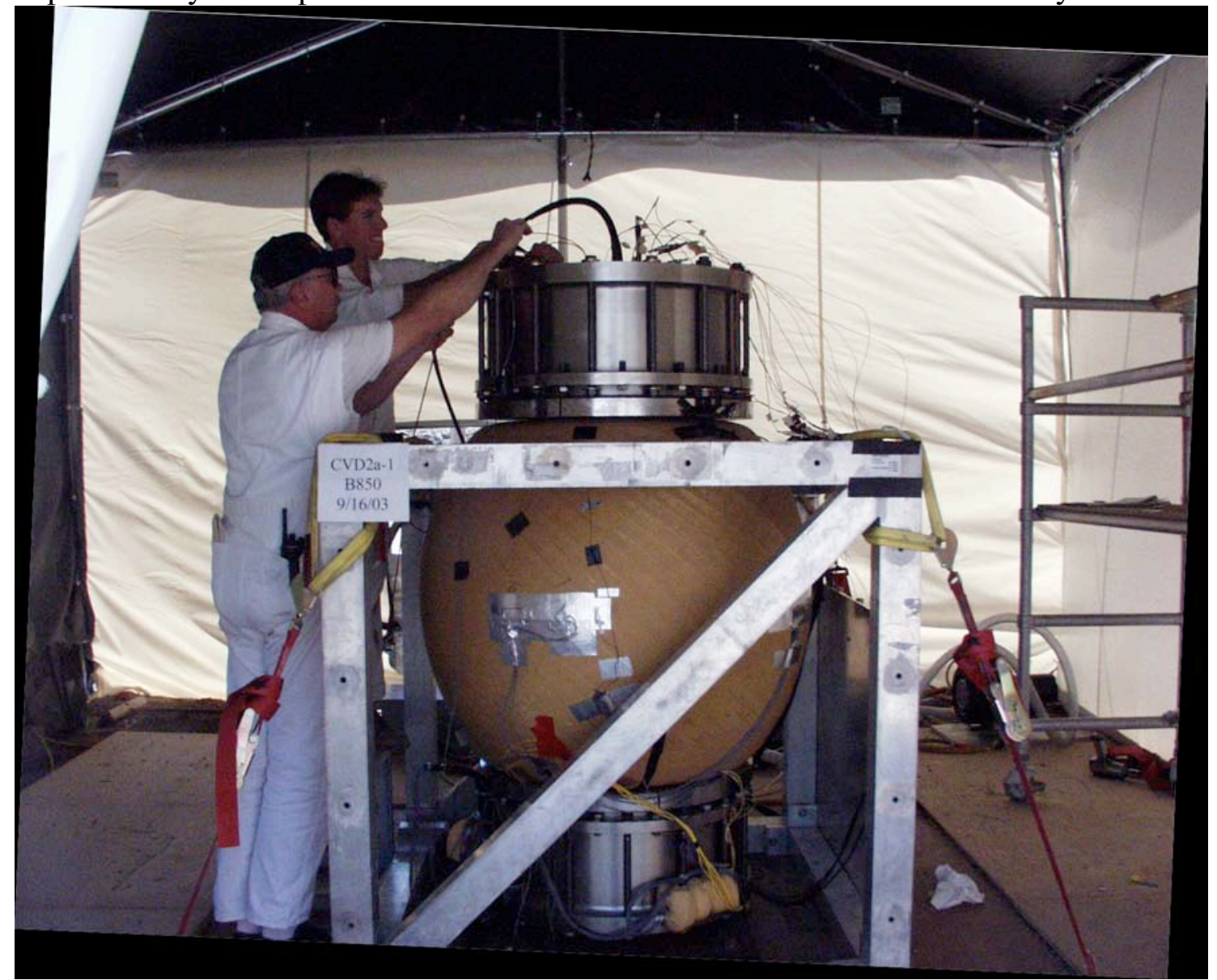

Figure 11. CVD-2a half scale Kevlar composite vessel in test stand

The CVD -2a vessel as seen in Figure 11, was then tested to $150 \%$ of the blast load and produced a peak blast pressure of $280 \mathrm{Mpa}(40 \mathrm{KSI})$. The vessel withstood the blast without damage. No damage to the welds or composite could be found.

To diagnose the leakage past the O-ring seals, small capillary tubes were monitored from each O-ring gap. Initially, this space was filled with pure nitrogen gas, while the full vessel was filled 
with a mixture of $10 \%$ Argon, $20 \%$ Oxygen, and $70 \%$ nitrogen. After the blast, the second Oring space had some argon, carbon monoxide and hydrocarbons present. However, the other $\mathrm{O}$ rings did not appear to leak. While there was a small amount of oxygen and argon in these spaces, there was no carbon monoxide or hydrocarbons present from the blast. The small amount of argon could be an experimental error or possibly be caused by an inward air leak as the flanges vibrated after the blast.

Following the blast tests, the vessel was carefully taken apart to look for signs of leakage. No visible external leakage was found, but there were some dark areas on the port surfaces where the steel plugs rubbed against the aluminum ports because of vessel vibrations during the blast. There were no signs of blast combustion products beyond the first two seals as seen in Figure 12.

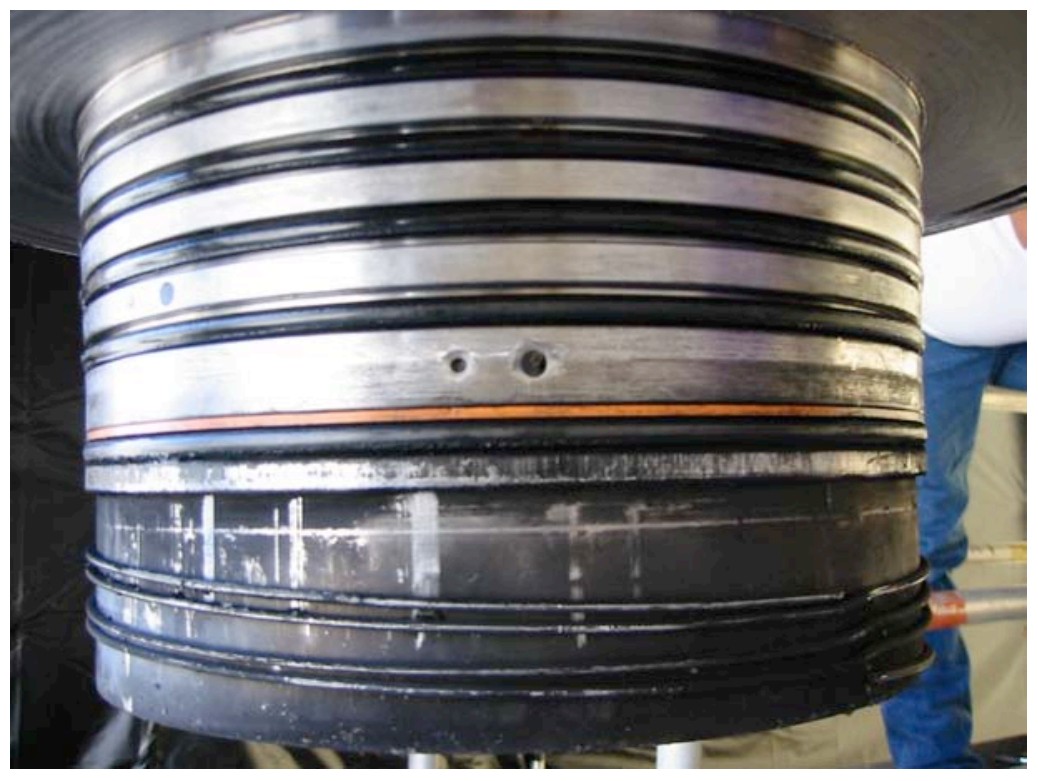

Figure 12. The top plug with sampling ports between the $O$-rings and evidence of particulate leakage past the first and second seals from the bottom.

\section{CONCLUSIONS}

After several years of development it now appears possible to utilize filament wound blast containment vessels that are light in weight and optically thin to X-rays or protons. Redundant port seals are used to meet strict environmental and safety standards comparable to those used 
for nuclear material shipping containers. These same composite design technologies can be applied to other containment vessels and to personnel shields subject to blast conditions.

\section{REFERENCES}

1) Henning et al., Seal Monitoring System for an Explosive Containment Vessel, imbid.

2) Grundler, Test Procedure for O-ring Interspatial Volume Test on CVD-2, LLNL report ERD03-167-AA (Nov. 11, 2003)

3) Hathcoat et, al, Empirical Measurements from the CVD-2a Test Series, LLNL Report ERD04-535-AA

4) Kokko, Edwin, Results 111402, LLNL Internal Presentation

5) Hagler, Lisle, Gauges1, Sept 24, 2003, LLNL Internal Presentation 